\title{
QUEEN'S
UNIVERSITY
BELFAST
}

\section{The experiences and support needs of people with intellectual disabilities who identify as LGBT: A review of the literature}

McCann, E., Lee, R., \& Brown, M. (2016). The experiences and support needs of people with intellectual disabilities who identify as LGBT: A review of the literature. Research in Developmental Disabilities, 57, 39-53. https://doi.org/10.1016/j.ridd.2016.06.013

Published in:

Research in Developmental Disabilities

Document Version:

Publisher's PDF, also known as Version of record

Queen's University Belfast - Research Portal:

Link to publication record in Queen's University Belfast Research Portal

\section{Publisher rights}

Copyright 2016 Elsevier.

This manuscript is distributed under a Creative Commons Attribution-NonCommercial-NoDerivs License

(https://creativecommons.org/licenses/by-nc-nd/4.0/), which permits distribution and reproduction for non-commercial purposes, provided the author and source are cited.

\section{General rights}

Copyright for the publications made accessible via the Queen's University Belfast Research Portal is retained by the author(s) and / or other copyright owners and it is a condition of accessing these publications that users recognise and abide by the legal requirements associated with these rights.

Take down policy

The Research Portal is Queen's institutional repository that provides access to Queen's research output. Every effort has been made to ensure that content in the Research Portal does not infringe any person's rights, or applicable UK laws. If you discover content in the Research Portal that you believe breaches copyright or violates any law, please contact openaccess@qub.ac.uk. 


\title{
The experiences and support needs of people with intellectual disabilities who identify as LGBT: A review of the literature
}

\author{
ABSTRACT \\ Background \\ People who identify as lesbian, gay, bisexual and transgender (LGBT) can face many \\ challenges in society including accessing education, care and support appropriate to \\ individual needs. However, there is a growing and evolving evidence base about the \\ specific needs of people with intellectual disabilities (ID) in this regard.
}

\begin{abstract}
Aims
The aim of this review was to explore the experiences of people with ID who identified as LGBT through an examination of studies that addressed their views and highlighted specific issues, concerns and service responses.
\end{abstract}

\section{Methods and procedures}

A comprehensive search of relevant databases from February 1995 to February 2015 was conducted. Studies were identified that met specific criteria that included: empirical peer reviewed studies, the use of recognized research methods and focused on people with ID whom identified as LGBT. The search yielded 161 papers in total. Following the removal of duplicates, 37 papers were screened using rigorous inclusion and exclusion criteria. Finally, 14 papers were considered suitable for the review.

\section{Outcomes and results}

The data were analysed and key themes identified that included accessing health services, gender and sexual identity, attitudes of people with ID regarding their LGBT status, and education, supports and therapeutic interventions. 


\section{Conclusions and Implications}

There is a need for service providers and carers to be more responsive to the concerns of people with ID who identify as LGBT to improve their health and well-being by reducing stigma and discrimination and by increasing awareness of their care and support needs. The implications are discussed in terms of policy, education, research and practice developments.

\section{Keywords:}

Intellectual disability, review, lesbian, gay, bisexual, transgender, service developments

\section{What this paper adds?}

There is a growing and evolving empirical evidence base regarding the experiences of people who identify as LGBT and have an ID. This paper raises many important issues that have been gleaned from research studies that sought to gain different viewpoints and establish the needs of LGBT people with an ID. The discussion highlights issues relevant to future research, practice, educational and policy initiatives and provides useful recommendations around socially inclusive practice.

\section{Introduction}

The evidence base regarding the experiences and views of people with intellectual disability (ID) who identify as lesbian, gay, bisexual and transgender, their support needs and service provision, is growing and evolving. Policy makers worldwide have attempted to address some of the issues in policies, reports and best practice guides related to the equality and human rights agenda (Department of Health 2009a, Health Service Executive 2009; Scottish Government 2013; World Health Organisation 2015). From a health perspective, people with ID experience a range of physical and mental health conditions that are more common than those experienced by the general population and requires access to health services (Kwok \& Cheung 2007, Young et al. 2007). Physical health conditions such as epilepsy, respiratory disorders, gastric disorders, sensory 
impairments, cardiovascular disease and diabetes are common, as is mental illness by way of anxiety disorders, depression, bipolar disorder, schizophrenia and dementia (Emerson \& Baines 2010; McCarron et al. 2011). However, despite identified higher health needs and poorer health, as a population, they experience barriers to accessing health services appropriate to the individual physical and psychosocial needs, with significant consequences to their health and well-being (Alborz et al., 2005; Brown et al., 2011). Furthermore, issues related to communication associated with cognitive impairment are common within the intellectually disabled population. The situation is further compounded by the ability of some to provide informed consent to treatment and further contributes to their disadvantage and acts as a potential barrier when seeking access to healthcare systems (Department of Health 2009b, Boardman et al. 2014). All of these issues provide distinct challenges to people with ID who identify as LGBT (Stoffelen et al. 2013).

LGBT people with ID are often subjected to what is acknowledged as 'layered stigma' . People with ID may experience stigma and discrimination as a result of their disability and impairments and because of their LGBT status (Bennett \& Coyle 2001), resulting in 'minority stress' (Meyer 2003). Prejudice and discrimination may create further marginalisation, social exclusion, and limit the opportunity for developing meaningful relationships (Hall 2010). This is particularly the case for people with more severe and complex ID (Mansell 2010). In terms of psychosocial wellbeing, existing studies demonstrate that LGBT people in the general population experience more psychological distress than heterosexuals and are at greater risk of mental health problems (King et al. 2008; Meyer 2010). Issues for concern include institutionalized prejudice, social stress, social exclusion, homophobic and transphobic hatred, bullying, and violence (David \& Knight 2008; Kuyper \& Fokkema 2011). There can be an increased susceptibility to 
alcohol and drug misuse as well as suicidality and issues related to self-harm (Cochran et al. 2003; Grant et al. 2011). In one study, Mayock et al. (2009) reported that $86 \%$ of the LGBT participants surveyed experienced depression at some point in their lives, with $25 \%$ taking prescribed medication, and $27 \%$ indicating that they had self-harmed at least once in their lives. However, many people developed resilient traits through experience that often strengthens their personal sense of well-being and quality of life (McCann \& Sharek 2014). Across the developed world there has been a shift away from institutional models of care to care in the community (Department of Health 2009a, Scottish Government 2013). With this move, the extent of the health inequalities experienced by people with ID has become increasingly apparent. As a result of their extended life expectancy and multi-morbidities, people with ID are high and frequent consumers of all healthcare services and the need to ensure that there is equality of access to universal health services and the provision of specialist ones when needed (Maulix et al., 2011; Scottish Government, 2013).

Despite the growing evidence base of the extent of their health needs and the positive moves arising from care located in the community, many continue to experience stigma, discrimination, social disadvantage and poor health (World Health Organization 2013). Today, many people with ID live relatively independently in the community, some in the family home, some may receive visiting social care support or others in 24 hour staffed accommodation (Prime Minister's Strategy Unit 2005, Department of Health 2009a, Scottish Government 2013). Whilst individual social care support needs may be addressed, it is evident that some family carers and social care support workers lack knowledge of the health conditions experienced by people with ID that adversely impacts on healthcare provision necessary for early identification and treatment options (Elderton \& Jones 2011). 


\section{Method}

\subsection{Research questions}

The aim of this review is to establish the views and experiences of people with ID who identify as LGBT and highlight issues that may guide future policy, education, supports and service provision. To address these aims, two questions were posed in this review of the literature:

1. What are the views and experiences of service users who have ID and identify as LGBT? 2. What are the policy, education, support and service responses necessary for people who have ID and identify as LGBT?

\subsection{Search and selection strategy}

An expert subject librarian was consulted. The systematic search of available studies was carried out using the following databases: CINAHL, MEDLINE, PsycINFO, PubMed and Sociological Abstracts. A search strategy was developed using the Boolean operators AND/OR within the following search string: intellectual disab* OR mental retard* OR mental deficiency OR mental handicap OR developmental disab* AND homosexual* OR gay OR lesbian* OR bisexual* OR transgender* OR transsexual* OR intersex OR queer OR LGBT. An example of the search strategy and results of one database is provided (Table 1) and this was applied to all of the other identified databases. *** Insert Table 1 here $* * *$

The searches resulted in 161 combined hits across the databases. The search outcomes are set out in Figure 1. All of the 161 papers identified were reviewed for their relevance; 37 titles and abstracts were reviewed against the inclusion criteria. The inclusion criteria were limited to academic journals, peer reviewed empirical studies and written in English. Studies had to focus specifically on the aims of the review by clearly highlighting the views and experiences of people with ID who identify as LGBT and the carer and service 
responses pertinent to their needs. Those papers that did not meet the criteria were excluded from the review. A hand search was also undertaken of the reference lists of the identified papers leaving a total of 14 papers for full review. The data were accessed from February 1995 to February 2015. Studies that used a qualitative, quantitative or mixed methods approach were considered for inclusion in the review.

$* * *$ Insert figure 1 here $* * *$

\subsection{Quality assessment}

Following identification of the studies the Critical Appraisal Skills System (Critical Appraisal Skills Programme, 2013) was used to provide an evidence-based framework to reviewing the papers and consistently applied the essential questions to each of the selected studies (Table 2). Similar to the approach used by Rushbrooke et al. (2014), each CASP question was scored zero, one or two out of a possible total of twenty points. A score of zero was given if the article contained no information, a score of one indicated a moderate amount of information and a score of two demonstrated that the article fully addressed the relevant question. A total of 6 out the 14 studies received a score of 17 or more highlighting the overall quality of each study (Abbott \& Burns 2007; Burn \& Davies 2011; LöfgrenMårtenson 2009; Löfgren-Mårtenson 2012; Parkes et al. 2009; Stoffelen et al. 2013). However, from a quality perspective, 6 studies received a CASP score ranging from 14-16 from a possible 20, indicating a lack of rigor in areas including appropriate data collection methods, research relationship considerations, ethical issues and the clarity of the findings (Abbott \& Howarth 2007; Bedard et al. 2010; Cambridge 1996; Elderton et al. 2014; McClelland et al. 2012; Withers et al. 2001). These are issues that need to be addressed in future research studies thereby seeking to improve the overall quality of the available research evidence. Two papers adopted case study designs (Edmonds \& Collins 1999; Stauffer-Kruse 2007) and received CASP quality scores of 8 respectively, primarily due to 
limited information related to study aims, recruitment, methods, ethics, analysis and findings which adversely affected the overall value of the research. However, the case studies highlight important issues in relation to the topic and the complexities involved in providing care and support for some people with ID. Following review, using the CASP, all papers $(n=14)$ were deemed relevant to the aims of the review.

$$
* * * \text { Insert Table } 2 \text { here } * * *
$$

\subsection{Characteristics of the selected studies}

The 14 studies that addressed the review questions are presented in Table 3 . The majority of the studies $(n=9)$ were carried out in the United Kingdom (UK), two studies were conducted in Sweden, two in Canada and one in the Netherlands. The selected studies had sample sizes ranging from single case studies to 71 participants involving people with ID, families and paid carers. A total of 11 studies used qualitative methods, including one-to-one interviews, focus groups and case studies (Abbott \& Burns 2007; Howarth 2007; Edmonds \& Collins 1999; Elderton et al. 2014; Löfgren-Mårtenson 2009; Löfgren-Mårtenson 2012; McClelland et al. 2012; Parkes et al. 2009; Stauffer- Kruse 2007; Stoffelen et al. 2013; Withers et al. 2001). Three studies used a quantitative approach (Bedard et al. 2010; Burns \& Davies 2011; Cambridge 1996). The reviewers adopted a pragmatic approach by including studies using different methodological approaches in order to allow for a fuller understanding of the diverse range of issues.

$* * *$ Insert Table 3 here $* * *$

\subsection{Data extraction and analysis}

The review process was guided by recognised methods involving the synthesis of mixed literature (Mays et al. 2005). The papers were analysed in the following ways. Initially, all themes relevant to the research questions were identified and coded from the results 
section of the papers. The identified themes were then grouped according to concepts to allow for comparison between themes both within and between each study. The themes were subsequently considered by the review team for verification and agreement.

\section{Findings}

Following analysis, five main themes were identified: (i) accessing and using services, (ii) gender and sexual identity, (iii) attitudes of people with ID regarding their LGBT status, (iv) sexual risk behaviours, (v) education, supports and therapeutic interventions.

\subsection{Accessing and using services}

In terms of engagement with health services and barriers to access, two studies specifically explored staff attitudes towards people who are LGBT and have an ID. Abbott and Howarth (2007) undertook a qualitative study involving interviews with staff ( $\mathrm{n}=71)$ to determine the supports available to service users in their care and found that most staff lacked confidence in discussing sexuality issues, possessed poor attitudes and needed education and training regarding the needs of people with ID. The second qualitative study, conducted in Sweden with a sample of $n=37$ comprising people with ID, their paid carers and families, revealed discriminatory attitudes, safety and vulnerability issues and a lack of guiding policies in terms of adult protection, sexual health and ID. The findings also identified a 'blind spot' regarding the expectations and visibility of people with ID when accessing heath services relevant to their sexual health needs and the need for the development of more inclusive strategies (Löfgren-Mårtenson 2009).

Both studies identified the need for staff training as well as organizational support for future practice developments that would address knowledge, skills and attitudes. In a review of 13 case records of people with ID undertaken by Parkes et al. (2009) in the UK, distinct physical and psychosocial challenges were identified for transgender people with 
ID around mental health concerns, tackling stigma and discrimination and accessing and using the extremely limited available services.

\subsection{Gender and sexual identity}

Whilst several studies addressed LGB experiences related to this theme, fewer explored issues relevant to people who identify as transgender. In the Swedish study, participants referred to the 'invisibility' of people who are LGBT and have an ID and issues around expressing and appreciating the rich variety of gender and sexual experiences that exist (Löfgren-Mårtenson 2009). In a UK study, staff alluded to the presumed 'asexual' status of people with ID (Abbott \& Howarth 2007). In contrast, positive traits were experienced by service-users such as resilience, confidence building, self-affirmation and self-acceptance in the UK study involving 10 men and 1 woman with ID (Elderton et al. 2014). Two studies, one undertaken in the UK (Parkes et al. 2009) and the other in the Netherlands (Stoffelen et al. 2013), identified significant traumatic life events and challenges faced by participants including childhood abuse, sexual abuse, physical assault and partner violence, highlighting the need for recognition of the existence of such issues within the population of people with ID who identify as LGBT and the provision of individualized assessment, therapy, treatment and support. In one study, exploring gender identities and sexual orientation, where 4 participants experienced gender dysphoria, practitioners were encouraged to explore gender and sexuality issues. The authors concluded that psychosocial supports should be available to all people with ID whom identify as LGB and T (Bedard et al. 2010).

\subsection{Attitudes of people with ID regarding LGB status}

In a quantitative study undertaken in the UK involving 27 women with ID, their attitudes towards people who identified as LGB were explored. The findings found that almost three quarters (74\%) of respondents lacked knowledge of LGB issues and a majority 
(70\%) held negative beliefs and attitudes towards people who are LGB (Burns and

Davies 2011). In contrast, in the case study undertaken by Edmonds \& Collins (1999) in

the UK, positive experiences were identified, such as, self-acceptance and self-

affirmation in relation to a person's LGB identity. In the Swedish study undertaken by

Löfgren-Mårtenson (2009) participants expressed unhappiness and difficulty accepting

their gay identity and were perceived by staff as possessing another 'deviation' and an

additional unnecessary disability.

\section{Invisibility}

Sexuality concerns are often ignored by service-providers with participants stating that they were made to 'feel invisible' in relation to their gay identity (Stauffer-Krause 2007; Stofflen et al. 2013). Six studies (Abbott \& Burns, 2007; Abbot \& Howarth, 2007; Burns \& Davies, 2011; Cambridge 1996; Edmonds \& Collins, 2007; Stoffelen et al. 2013) identified the need for and the importance of the education of people with ID about sexual practices, risks and forming and maintaining intimate relationships and the need for education and practice development for families and staff involved in their care and support. These aspects were seen in the context of equality, empowerment and social inclusion. In one study involving interviews with 20 people with ID, participants were encouraged and very able to articulate their thoughts and feelings about sexuality issues including coming out, staff and family responses to sexual concerns, intimacy and future hopes and dreams (Abbott \& Burns 2007). Study recommendations included more inclusive and LGB affirmative practices and appropriate staff education and training.

\subsection{Sexual risk behaviors}

In a quantitative study undertaken by Cambridge (1996) in the UK, investigating 'risky'sexual behaviours among men who have sex with other men, the findings indicated that a significant number of participants (90\%) had sex with other men with an ID and that 
three quarters (75\%) had engaged in 'risky' sexual activities. Nearly one third (33\%) of the study participants had been sexually abused. The author recommends education and training for people with ID and their families and paid carers. The findings also identified the need for the development of guiding policies that take into account safety and vulnerability factors faced by men with ID who have sex with other men and highlighted the need for the development of accessible and targeted resources tailored specifically to the needs of men ID who are LGBT.

\subsection{Education, supports and therapeutic interventions}

The issue of supports and therapeutic interventions for people with ID and support for families and paid carers was a theme identified in five of the studies included in this review (Abbott \& Burns 2007; Abbott \& Howarth 2007; Parkes et al. 2009; StaufferKruse 2007; Withers et al. 2001). In the qualitative study undertaken by Withers et al. (2001) in the UK of a support group for men with ID who have sex with other men, the main issues highlighted were sexual identity, sexual health and mental health, including depression, anxiety and suicidality. All participants found the group helpful and liked that it was service-user led, supportive and empowering. The recommendations arising from the study were improving supports to families and paid carers through education initiatives and peer support groups, with increased access to talking therapies and specific LGBT support networks and the identification of sexual knowledge and behaviours of LGBT men with ID. In terms of educational initiatives, one study conducted in Sweden identified issues related to heteronormative assumptions that increases the invisibility or further marginalization of ‘gay’ people with ID (Löfgren-Mårtenson 2012). The interviews revealed that the sexual experiences of people with ID tended to focus on sexual risks rather than encouraging and supporting dialogue around pleasure, desire and intimacy. Abbott \& Howarth (2007) and Abbott \& Burns (2007) identified the need for 
service managers to provide support for staff in their organizations when working with service users with ID who are LGBT, with Parkes et al. (2009) focusing more specifically on the support needs of people with ID with gender dysphoria and who cross-dress. From the perspective of psychological support, Stauffer- Kruse (2007) identified the need for developments in this area for gay men with ID. Given the range of mental health and psychological issues that can be experienced by people with ID and notably gay men with ID, there is a need to focus on developing services appropriate to their needs.

\section{Discussion}

The review has highlighted key issues for people with ID who identify as LGBT in terms of specific health and social care needs. The findings highlight challenges in terms of further research, policy, education and practice developments.

\subsection{Research}

It is evident from this review of the literature that there is a requirement for a sustained and specific research-focus on the needs of people with ID who identify as LGBT to further identify support mechanisms, interventions and service responses that meet their distinct needs. Developing the evidence-base in this area is important given the significant changes that have taken place over the recent decades with regards to the move away from institutional to community-based models of care and the wider social inclusion of people with ID. When coupled with the developments and changes in the lives of LGBT people in general by way of their Human Rights and equality, the needs of people with ID require attention. The majority of the studies that formed this review were undertaken using qualitative $(\mathrm{n}=11)$ designs, employing one-to-one interviews, focus groups and case studies. The remaining studies $(n=3)$ used quantitative surveys; there were no mixed method studies. 
There was an absence of intervention and evaluation studies. The samples sizes across all the studies ranged from single case studies (Edmonds \& Collins 1999; Stauffer-Kruse 2007) through to a sample of $n=71$ in the study involving individual staff interviews by Abbot \& Howarth (2007). The studies tended to focus on gay men with ID and there was a limited focus on lesbians and transgender people with ID. There was an absence of epidemiological studies and only one evaluation study focusing on a support group for gay men with ID (Withers et al., 2001). There were no multi-centre national or international studies or longitudinal studies and no policy analysis studies examining how the needs of LGBT people with ID have or are being addressed and analyzing the impact and outcomes of policy. There are therefore important gaps that need to be addressed in the understanding of the needs of people with ID and how they can be more effectively met in the future. Table 4 sets out opportunities for further research on LGBT people with ID.

***Insert Table 4 here***

The importance of education and training was recognised in six studies (Abbott \& Burns 2007; Abbot \& Howarth 2007; Burns and Davies 2011; Cambridge 1996; Edmonds \& Collins 1999; Stoffelen et al. 2013). Further enquiry is therefore needed on the effectiveness and impact of education and training provided for people with ID, their families and carers and practitioners, with an opportunity to undertake pre and post evaluation studies of education and training, thereby measuring longer term outcomes and their benefits. Given the health inequalities and high health needs of people with ID and the issues related to abuse and mental illness identified in this review, there is a need to research the effectiveness of treatments and interventions in areas such as the treatment of HIV and psychological interventions for mental illness, trauma and abuse and individual and family support. Another important limitation of the studies included in this review is their relatively small sample sizes. There is therefore scope to undertake studies that are 
multi-centred to enable larger samples with a national, international and transcultural element.

\subsection{Policy Development}

There have been significant changes and developments in recognising the human rights of LGBT people, and legislation to prevent discrimination exists in many countries worldwide (World Health Organization 2013). With these developments is equality and freedom to express a gay identity and sexual behaviours; for some this can be a difficult and complex process (Kuyper \& Fokkema 2011; McNeil et al. 2012). From this literature review, it is apparent that this is often the case for people with ID who identify as LGBT. While specific ID policy has been developed in many countries that have influenced the move to community living, the issue of their sexuality and in particular those who are LGBT has attracted limited attention (Equality Authority 2002; Coleman et al. 2011; Department of Health 2013, Scottish Government 2013). Given the body of evidence regarding their health inequalities and health needs, this is a gap that needs to be addressed, including those related to sexual health (Health Service Executive 2009; Emerson \& Baines 2010). Concerns may exist from families and support workers due to the cognitive impairment experienced by people with ID and issues related to their vulnerability, capacity and consent and concerns regarding exploitation and abuse. Acknowledging child and adult protection concerns which on one hand seek to protect individuals from harm and on the other enabling independence so people with ID can express their sexuality and experience sexual relationships is necessary. In some countries, specific legislation and policy is in place to better support vulnerable adults at risk of harm and abuse (World Health Organization 2015), and for specialist Intellectual Disability Services to support mainstream sexual health and social care services to provides access to specialist capacity 
assessment, and supports for LGBT people with ID and more complex care needs (Slevin et al., 2007; Slevin et al., 2008).

Arising from this review is the need to ensure that sexual health and ID policies take account of and reflect the sexual health needs of people with ID. This requires policy responses to ensure that services take account of their care and support needs and can make reasonable adjustments to ensure equal access that recognizes that some people with ID may also be LGBT (Redley et al., 2012; World Health Organization 2013). Intellectual Disability- specific policy needs to ensure that the sexual needs of people with ID are reflected so that specialists work collaboratively with sexual health practitioners in areas such as shared assessments, the provision of psychological therapies, advising on capacity and consent issues and enabling sexual health information to be presented in an accessible format and that additional support is available to manage complex cases (Withers et al. 2001; Elderton et al. 2014). Acknowledging the potential presence of internalised homophobia by some people with ID and the existence of transphobia and to have in place strategies to support people Meyer 2003; Kuyper \& Fokkema 2011). Robust policy responses are necessary to ensure that double discrimination is addressed to prevent does prejudice towards people with ID and those are also LGBT, thereby avoiding further disadvantage.

\subsection{Practice}

It is necessary for all care services to recognize that people with ID can also be LGBT and that paternalism, heteronormativity, prejudice and negative attitudes may exist within organisations (Jukes \& Aldridge 2006; Gomes 2012). Creating opportunities for practitioners to discuss issues such as sexual identity, LGBT relationships, and concerns about vulnerability in relation to exploitation and abuse is necessary if the aspirations of LGBT people with ID are to be realized (Boardman et al. 2014). Challenging negative 
attitudes and stereotypes from people with ID, families and practitioners is important to minimise the potential for double discrimination and stigma arising from the ID and LGBT labels (Kline \& Preston-Shoot 2012). Local policies therefore need to recognize that some people with ID may also be LGBT and reflect anti-discriminatory practice to promote equality, full social inclusion and Human Rights.

From a support perspective, the expression of sexual identity by people with ID will require additional time and resources. To achieve this, collaborative working and support across care services, sexual health services and specialist intellectual disability services will be necessary for some people with ID. From this review, it is evident that people with ID are sexually active; some are LGBT and some men with ID have sex with other men. There is evidence of 'risky' sexual behaviours and a need to ensure that sexual health needs are fully assessed, treatment provided and additional supports made available. Some LGBT people with ID experience mental illness such as depression and anxiety disorders, an issue reflected in the intellectual disability mental health literature (Whitaker \& Read 2006, Mental Health Commission 2009). There is evidence of sexual abuse and partner abuse and services and practitioners need to be alert to the possibility and create opportunities to explore and discuss the issues with people with ID (Sequeria \& Hollins 2003, Cambridge et al., 2011). Access to specialist assessment, treatment and therapy for mental illness as well as access to therapy, effective in addressing distress and trauma related abuse may be needed (Department of Health and Children 2006; Bhaumik et al. 2011). Practitioners should promptly implement procedures to safeguard and protect the vulnerable from harm and ensure that appropriate support is available. An important role of practitioners is facilitating access to sexual health services and to local LGBT networks and support groups, such as those focusing on gay men's health. Collaborative working 
with LGBT community networks and support groups will enable LGBT people with ID to access mainstream LGBT services and to develop ID- specific services.

\subsection{Education}

LGBT people with ID require education and support, for example, to express their sexuality when adapting to their sexual identity. Families and support workers often have limited knowledge about the health of people with ID that may include their sexual health needs

(Wark et al., 2014). There should be access to education about being LGBT, sexuality and relationship concerns, and the opportunity to discuss pertinent issues regarding the LGBT person with ID. Induction programmes for practitioners in primary care, sexual health and support services should include areas such as the needs of people with ID, social inclusion and additional supports, LGBT sexuality issues, the role of specialist intellectual disability services, and local safeguarding and adult protection policies (Cambridge 1996, Philips et al., 2004, Barr \& Gates 2008).

For practitioners in specialist intellectual disability services, there is an opportunity to undertake education and training with colleagues in sexual health services, thereby sharing knowledge and skills and developing an understanding about their services and how LGBT people with ID can be better supported (McMurray \& Beebee 2007, Burns \& Davies 2011). This will enable practitioners in specialist intellectual disability services to work in partnership with LGBT people with ID, their families and care services and provide assessment, treatments, interventions and supports that takes accounts of the needs of the population in a way that is person-centred and reasonable adjustments made (Jukes \& Aldridge 2006, Turner \& Robinson 2011). Providing information in an accessible format is necessary on issues such as sexual identity, being LGBT, sexual behaviours, relationships and practices, sexual health and sexual health services, access to advice and support, safeguarding and adult protection. 


\subsection{Strengths and limitations of the review}

There is an increased interest in the experiences and needs of people with an ID identifying as LGBT, and the evidence base continues to grow and evolve. This review has uncovered important concerns that can guide and inform policy, education, practice and the support needs of people with ID who identify as LGBT as part of the drive towards more socially inclusive and responsive care. In terms of available evidence, limitations exist due to the robustness of the study designs, which can be inherent in undertaking research with this population. While seeking to be rigorous in terms of the quality review process, the authors acknowledge potential subjectivity, and to address this, a recognized framework was applied consistently throughout. Furthermore, the primary focus of this review concerned the needs and experiences of people with ID who identify as LGBT; the authors recognize the established body of evidence around the concept of sexuality, however this was outside the scope of the current review and is an area that will require further attention.

\section{Conclusion}

It is apparent from the findings from this review that people with ID who identify as LGBT still face significant challenges in terms of their sexual expression and identity. In terms of human rights, social inclusion and equality initiatives, opportunities exist to better support the specific health and social care needs of people who identify as LGBT. Education initiatives targeting knowledge and skills development for service personnel as well as focusing on tackling discrimination and prejudice have been proposed. Government policies need to be inclusive, empowering and rights-based (Institute of Medicine 2011; World Health Organization 2013). LGBT people with ID are sexually active and their sexual health and support needs should be recognised and supported in ways that are person-centred, respects human rights and dignity, while being responsive to adult protection concerns. The provision 
of appropriate psychological interventions is an area requiring attention, as is the need for access to and development of social networks and support groups. Innovative approaches to quality supports and interventions should be available to this population and become the main focus for future research.

\section{Acknowledgements}

To be added following peer review.

\section{Conflict of interest}

The authors declare no conflict of interest.

\section{References}

Abbott, D. \& Burns, J. (2007) What's love got to do with it? Experiences of lesbian, gay and bisexual people with intellectual disabilities in the United Kingdom and staff who support them. Sexuality Research and Social Policy 4 (1), 27-39.

Abbott, D. \& Howarth, J. (2007) Still off-limits? Staff views on supporting gay, lesbian and bisexual people with intellectual disabilities to develop sexual and intimate relationships. Journal of Applied Research in Intellectual Disabilities 20,116-126.

Alborz A., McNally, R. \& Glendinning, C. (2005) Access to health care for people with learning disabilities in the UK: Mapping the issues and reviewing the evidence. Journal of Health Services Research and Policy 10 (3), 173-182.

Barr, O. \& Gates, B. (2008) Education for the future: The changing face of education for staff, Tizard Learning Disability Review 13 (1), 18-27.

Bhaumik, S., Gangadharan, S., Hiremath, A., Swamidhas, P. \& Russell, S. (2011) Psychological treatments in intellectual disability: the challenges of building a good evidence base. The British Journal of Psychiatry 198 (6), 428-430.

Bedard, C., Zhang, H.L. \& Zucker, K.J. (2010) Gender Identity and Sexual Orientation in People with Developmental Disabilities. Sexuality and Disability 28, 165-175.

Bennett, C.J. \& Coyle, A. (2001) A minority within a minority: Identity and well-being among gay men with learning disabilities. Lesbian and Gay Psychology Review 2 (1), 9-15.

Boardman, L., Bernal, J. \& Hollins, S. (2014) Communicating with people with intellectual disabilities: A guide for general psychiatrists. Advances in Psychiatric Treatment 20 (1) 27-

36.

Brown, M., Duff, H., Karatzias, T. \& Horsburgh, D. (2011) A review of the literature relating to psychological interventions and people with intellectual disabilities: Issues for 
research, policy, education and clinical practice. Journal of Intellectual Disabilities 15(1), $31-45$.

Burns, J. \& Davies, D. (2011) Same-sex relationships and women with intellectual disabilities. Journal of Applied Research in Intellectual Disabilities 24, 351-360.

Cambridge, P. (1996) Men with learning disabilities who have sex with men in public places: mapping the needs of services and users in South East London. Journal of Intellectual Disability Research 40, 241-251.

Cambridge, P., Beadle-Brown, J., Milne, A., Mansell, J. \& Whelton, B. (2011) Patterns of risk in Adult Protection referrals for sexual abuse and people with intellectual disability. Journal of Applied Research in Intellectual Disabilities 24, 118-132.

Cochran, S. D., Sullivan, J. G. \& Mays, V. M. (2003) Prevalence of mental disorders, psychological distress, and mental health services use among lesbian, gay, and bisexual adults in the United States. Journal of Consulting and Clinical Psychology, 71 (1), 5361.

Coleman, E., Bockting, W., Botzer, M., Cohen-Kettenis, P., DeCuypere, G., Feldman, J. et al. (2011) Standards of Care for the Health of Transsexual, Transgender, and GenderNonconforming People, Version 7. International Journal of Transgenderism, 13, 165-232.

Critical Appraisal Skills Programme (2013) Ten questions to help you make sense of qualitative research. Oxford: Critical Appraisal Skills Programme.

David, S. \& Knight, B. G. (2008). Stress and coping among gay men: Age and ethnic differences. Psychology and Aging, 23 (1), 62-69.

Department of Health and Children. (2006) A Vision for Change: Report of the Expert Group on Mental Health Policy. Dublin: Stationery Office.

Department of Health (2009a) Valuing People Now: A New Three Year Strategy for People with Learning Disabilities. Making it Happen for Everyone. London: HMSO.

Department of Health (2009b). Healthcare for all: The Independent Inquiry into Access to

Healthcare for People with Learning Disabilities. London: HMSO.

Department of Health (2013) Healthy Ireland: A framework for improved health and well- being 2013-2025. Dublin: Department of Health.

Edmonds, C. \& Collins, A. (1999) Using social and educational approaches to enable a man with learning disabilities to develop his sexual identity and orientation. British Journal of Learning Disabilities 27 (4), 127-131.

Elderton, A., Jones, C. (2011) A safe place and a gay space: the Oxfordshire Mingle Group. Learning Disability Practice 14, 14-17. 
Elderton, A., Clarke, S., Jones, C., Stacey, J. (2014) Telling our story: A narrative therapy approach to helping lesbian, gay, bisexual and transgender people with a learning disability identify and strengthen positive self-identity stories. British Journal of Learning Disabilities 42 (4), 301-307.

Emerson, E. \& Baines, S. (2010) Health inequalities and people with learning disabilities in the UK: 2010. Durham: Improving Health \& Lives: Learning Disabilities Observatory.

Equality Authority (2002) Implementing equality for lesbians, gays and bisexuals. Dublin: Equality Authority.

Gomes, M.T. (2012) The S Words: Sexuality, Sensuality, Sexual Expression and People with Intellectual Disability. Sexuality and Disability 30 (2), 237-245.

Grant, J. M., Mottet, L. A. \& Tanis, J. (2011) Injustice at Every Turn: A Report of the National Transgender Discrimination Survey. Washington, DC: National Center For Transgender Equality.

Hall, E. (2010) Spaces of social inclusion and belonging for people with intellectual disabilities. Journal of Intellectual Disability Research 54 (Supplement 1), 48-57.

Health Service Executive (2009) LGBT Health: Towards Meeting the Health Care Needs of Lesbian, Gay: Bisexual and Transgender People. Dublin: Health Service Executive.

Jukes, M. \& Aldridge, J. (Eds) (2006) Person-Centred Practices: A Therapeutic Perspective.

London: Quay Books.

King, M., Semlyen, J., Tai, S.S., Killaspy, H., Osborn, D., Popelyuk, D. \& Nazareth, I. (2008) A systematic review of mental disorder, suicide, and deliberate self harm in lesbian, gay and bisexual people. BMC Psychiatry 8, 1-17.

Kline R. \& Preston-Shoot M. (2012) Professional Accountability in Social Care and Health: Challenging Unacceptable Practice and its Management. London: Sage.

Kuyper, L., \& Fokkema, T. (2011). Minority stress and mental health among Dutch LGBs: examination of differences between sex and sexual orientation. Journal of Counseling Psychology 58 (2), 222-233.

Kwok, H. \& Cheung, K. (2007) Co-morbidity of psychiatric disorder and medical illness in people with intellectual disabilities. Current Opinion in Psychiatry 20443-449.

Löfgren-Mårtenson, L. (2009) The invisibility of young homosexual women and men with learning disabilities. Sexuality and Disability 27, 21-26.

Löfgren-Mårtenson, L. (2012) “I want to do it right!” A pilot study of Swedish sex education and young people with intellectual disabilities. Sexuality and Disability 30, 209-225. 
Mansell J. (2010) Raising our sights: Services for adults with profound intellectual and multiple disabilities. Tizard Learning Disability Review 15 (3), 5-12.

Maulix P., Mascarenhas M., Mathers C., Dua T. \& Saxena S. (2011) Prevalence of intellectual disability: A meta-analysis of population-based studies. Research in Developmental Disabilities 32, 419-436.

Mayock, P., Bryan, A., Carr, N. \& Kitching, C. (2009). Support-ing LGBT Lives: A Study of the Mental Health and Well-Being of Lesbian, Gay, Bisexual and Transgender People. Dublin: Gay and Lesbian Equality Network (GLEN) and BeLonG To Youth Service.

Mays, N., Pope, C. \& Popay, J. (2005) Systematically reviewing qualitative and quantitative evidence to inform management and policy-making in the health field. Journal of Health Services Research and Policy 10 (Suppl. 1), 6-20.

McCann, E. \& Sharek, D. (2014) A survey of lesbian, gay, bisexual and transgender people's experiences of mental health services in Ireland. International Journal of Mental Health Nursing, 23 (2), 118-127.

McCarron, M., Swinburne, J., Burke, E., McGlinchey, E., Mulryan, N., Andrews, V., Foran S. \& McCallion, P. (2011) Growing Older with an Intellectual Disability in Ireland

2011: First Results from The Intellectual Disability Supplement of The Irish Longitudinal Study on Ageing. Dublin: School of Nursing \& Midwifery, Trinity College Dublin.

McClelland, A., Flicker, S., Nepveux, D., Nixon, S., Wilson, C., Marshall, Z., Travers, R. \& Proudfoot, D. (2012) Seeking safer sexual spaces: Queer and trans young people labeled with intellectual disabilities and the paradoxical risks of restriction. Journal of Homosexuality 59 (6), 808-819.

McMurray, A. \& Beebee, J. (2007) Learning disability awareness training for hospital staff. Learning Disability Practice 10, 10-14.

McNeil, J., Bailey, L., Ellis, S., Morton, J. \& Regan, M. (2012). Trans Mental Health and Emotional Wellbeing Study 2012. Edinburgh: Equality Network.

Mental Health Commission (2009) Code of Practice: Guidance for Persons working in mental health services with people with intellectual disabilities. Dublin: Mental Health Commission.

Meyer, I. H. (2003) Prejudice, social stress, and mental health in lesbian, gay, and bisexual populations: Conceptual issues and research evidence. Psychological Bulletin 129 (5), 674-697.

Meyer, I. H. (2010). Identity, stress, and resilience in lesbians, gay men, and bisexuals of color. The Counseling Psychologist, 38 (3), 442-454.

Parkes, G. \& Wilson, D. (2009) Cross dressing and gender dysphoria in people with learning disabilities: a descriptive study. British Journal of Learning Disabilities 37, 151156. 
Philips A., Morrison J. \& Davis R. (2004) General Practitioners educational needs in intellectual disability health. Journal of Intellectual Disabilities Research 48, 142-9.

Prime Minister's Strategy Unit (2005) Improving the Life Chances of Disabled People. HMSO: London.

Medley, M., Maine, E., keeling, A. \& Pattni, P. (2012) The voting rights of adults with intellectual disabilities: reflections on the arguments, and situation in Kenya and England and Wales. Journal of Intellectual Disability Research. 56(11), 1026-35.

Rushbrooke, E., Murray, C. \& Townsend, S. (2014) What difficulties are experienced by caregivers in relation to the sexuality of people with intellectual disabilities? A qualitative meta-synthesis. Research and Developmental Disabilities 35, 871-886.

Scottish Government (2013) The Keys to Life. Edinburgh: The Stationery Office.

Sequeria H. \& Hollins S. (2003) Clinical effects of sexual abuse on people with

learning

disabilities: Critical literature review. British Journal of Psychiatry 182, 13-19.

Slevin, E., McConkey, R., Truesdale-Kennedy, M., Barr, O. \& Taggert, L. (2007) Community Learning Disability Teams: Perceived effectiveness, multidisciplinary working and service user satisfaction. Journal of Intellectual Disability Research 11, 329-42.

Slevin, E., Truesdale-Kennedy, M., McConkey, R.,Barr, O. \& Taggart, L. (2008) Community learning disability teams: Developments, composition and good practice. $A$ review of the literature. Journal of Intellectual Disabilities 12 (1), 59-79.

Stauffer-Kruse, S. (2007) Gay men with learning disabilities: UK service provision. Journal of Gay and Lesbian Psychotherapy 11 (1-2), 145-152.

Stoffelen, J., Kok, G., Hospers, H. \& Curfs, L.M.G. (2013) Homosexuality among people with a mild intellectual disability: An explorative study on the lived experiences of homosexual people in the Netherlands with a mild intellectual disability. Journal of Intellectual Disability Research 57 (3), 257-267.

Turner, S. \& Robinson, C. (2011) Reasonable Adjustments for People with Learning Disabilities: Implications and Actions for Commissioners and Providers of Healthcare. Lancaster: Learning Disability Health Observatory.

Wark, S., Hussain, R. \& Edwards, H. (2014) The training needs of staff supporting individuals ageing with intellectual disability. Journal of Applied Research in Intellectual Disabilities 27 (3), 273-288.

Whitaker, S. \& Read, S. (2006) The prevalence of psychiatric disorders among people with intellectual disabilities: An analysis of the literature. Journal of Applied Research in Intellectual Disabilities 19, 330-45. 
Withers, P., Ensum, I., Howarth, D., Krall, P., Thomas, D. \& Weekes, D. (2001) A psychoeducational group for men with intellectual disabilities who have sex with men. Journal of Applied Research in Intellectual Disabilities 14, 327-339.

World Health Organization (2013) Addressing the causes of disparities in health service access and utilization for lesbian, gay, bisexual and trans (LGBT) persons. Geneva: WHO.

World Health Organization (2015) The European Health Report 2015: Targets and beyond- reaching frontiers in evidence. Geneva: WHO.

Young, A.F., Chesson, R.A. \& Wilson, A.J. (2007) People with learning disabilities, carers and care workers awareness of health risks and implications for primary care. Family Practice 24 (6), 576-584 
